\title{
Inventarisasi Tumbuhan Mangrove di Kampus Institut Teknologi Sepuluh Nopember
}

\author{
Ardhiani Al Syauqi dan Kristanti I. Purwani \\ Departemen Biologi, Fakultas Ilmu Alam, Institut Teknologi Sepuluh Nopember (ITS) \\ e-mail:dosen_pembimbing@jurusan.its.ac.id
}

\begin{abstract}
Abstrak-Institut Teknologi Sepuluh Nopember (ITS) Surabaya sejak 2011 mengusung ITS eco campus. Salah satu karakteristi eco campus adalah adanya pemanfaatan lahan terbuka hijau. Pemanfaatan lahan terbuka hijau di wilayah kampus digunakan sebagai bahan kajian keanekaragaman tumbuhan. Upaya mengkaji keanekaragaman tumbuhan salah satunya dengan menginventarisasikan tumbuhan di kampus ITS. Salah satu jenis tumbuhan yang ada di kampus ITS adalah tumbuhan pesisir atau lebih dikenal dengan mangrove. Tujuan dari penelitian ini adalah mengetahui jumlah tumbuhan mangrove di kampus ITS. Mengetahui taksonomi tumbuhan mangrove di kampus ITS. dan mengetahui manfaat mangrove ITS. Tujuan dari penelitian ini adalah mengetahui jumlah tumbuhan mangrove di kampus ITS. Mengetahui taksonomi tumbuhan mangrove di kampus ITS. dan mengetahui manfaat mangrove ITS. Penelitian ini menggunakan metode jelajah dan analisis deskriptif kualitatif. Terdiri atas 12 familia yaitu Rhizophoraceae, Pteridaceae, Lecythidaceae, Asclepiadaceae, Apocynaceae, Malvaceae, Rubiaceae, Pandanaceae, Passifloraceae, Euphorbiaceae, Verbenaceae, dan Combretaceae. Manfaat dari mangrove di kawasan kampus ITS sebagian besar sebagai tanaman obat, pangan, dan bahan bangunan. Meskipun begitu ada beberapa jenis mangrove yang bermanfaat dibidang pertanian.
\end{abstract}

Kata Kunci-Eco campus, inventarisasi, kampus ITS, mangrove.

\section{PENDAHULUAN}

K AMPUS ITS sudah sejak 2011 menerapkan komitmen mengusung ITS eco campus yang sekarang berubah menjadi ITS smart eco campus, menjadikan kawasan kampus sebagai area ramah lingkungan dan tempat pelestarian tumbuhan. Menurut Badan Lingkungan Hidup (BLH) Surabaya eco campus didefinisikan sebagai kampus yang telah peduli dan berbudaya lingkungan dan telah melakukan pengelolaan lingkungan secara sistematis dan berkesinambungan. Setiap tahun ITS rutin mengadakan penanaman pohon sejak mengusung eco campus. Meskipun sebelumnya kawasan ITS sudah memiliki hutan kampus yang memiliki keanekaragaman tumbuhan. Beberapa tumbuhan diantaranya adalah tanaman pesisir atau lebih dikenal dengan mangrove.

Mangrove merupakan tumbuhan pesisir yang memiliki banyak fungsi, diantaranya adalah fungsi fisik, biologi, dan ekonomi. Fungsi fisiknya yaitu untuk menjaga kondisi pantai agar tetap stabil, melindungi pantai dan tebing pantai, mencegah terjadinya abrasi dan instrusi air laut, serta sebagai penangkap zat - zat dari laut sebelum ke darat. Fungsi biologinya adalah sebagai habitat benih ikan, udang, dan kepiting untuk hidup dan mencari makan. Selain hewan akuatik tersebut mangrove juga dapat dijadikan sumber keaneka ragaman biota lainnya seperti burung, ular, kera, beberapa jenis anggrek. Sedangkan fungsi ekonomi mangrove sudah sejak lama dimanfaatkan oleh penduduk pesisir sebagai bahan bakar (kayu, arang), bahan bangunan (balok, papan), bahan pewarna tekstil, serta diolah menjadi bahan pangan dan obat - obatan [1].

Hutan kampus termasuk dalam hutan kota yang bertujuan sebagai tempat area hijau. Pemanfaatan area hijau pada hutan kampus biasanya dimanfaatkan sebagai bahan kajian untuk pelestarian lingkungan, pemanfaatan tanaman organik, dan keaneka ragaman tumbuhan dan hewan [2].

Oleh karenanya perlu adanya kajian inventarisasi tumbuhan mangrove yang ada di hutan kampus ITS sebagai upaya untuk penyedia data tentang keberadaan mangrove dan lokasinya. Selain itu juga kedepannya dapat dijadikan referensi untuk kajian kandungan dan pemanfaatannya.

\section{METODE PENELITIAN}

\section{A. Waktu dan Tempat Penelitian}

Penelitian ini dilaksanakan pada bulan Juli 2017 di kawasan Kampus ITS dan Labolatorium Biosains dan Teknologi Tumbuhan Jurusan Biologi Institut Teknologi Sepuluh Nopember Surabaya.

\section{B. Alat dan Bahan}

Alat yang digunakan dalam penelitian ini adalah pensil, kertas, plastik, penggaris, etiket gantung, dan kamera. Bahan yang digunakan dalam penelitian ini adalah bunga, daun, buah, batang, dan akar dari spesies mangrove di kampus ITS dan alkohol.

\section{Cara Kerja \\ 1) Pengambilan Sampel}

Pengambilan sampel dilakukan dengan metode jelajah, yaitu metode yang dilakukan dengan menjelajah seluruh wilayah kampus ITS. Tahapannya adalah dengan membagi wilayah observasi menjadi empat area, gambar 1. Pembagian area berdasarkan kerapatan vegetasi tumbuhan pada setiap area.

Pada area hutan kampus titik awal jelajah dimulai dari stadion ITS. Menyusuri jalan yang tersedia di hutan kampus ITS. Jalan berbentuk pematang sawah, sehingga mempermudah pengamatan hingga kembali ke titik awal.

Pada area gedung kampus titik awal dimulai dari gedung $\mathrm{H}$ jurusan Biologi. Mengikuti denah gedung ITS, jelajah di area 
gedung kampus dilakukan dengan mengelilingi setiap gedung, supaya setiap tumbuhan yang berada di sekitar gedung kampus teramati.

Pada area III yang meliputi gedung Nasdec, Robotika, dan Hidrodinamika, jelajah dimulai dari mengelilingi gedung Robotika dan lingkungan sekitarnya. Kemudian berjalan menuju gedung Nasdec dan gedung Hidrodinamika.

Area IV merupakan area perumahan dosen dan asrama mahasiswa ITS. Area ini secara kondisi lebih mudah dijelajahi, karena memiliki jalan yang lebar bahkan bisa dilalui sepeda motor. Titik awal dimulai dari perumahan dosen blok $\mathrm{U}$, lalu menyusuri jalan ke arah selatan menuju perumahan dosen blok T. selanjutnya menuju arah barat hingga asrama mahasiswa ITS.

Dalam menjelajahi wilayah kampus ITS, akan ditemukan berbagai macam tumbuhan. Tumbuhan yang termasuk dalam tumbuhan mangrove diambil gambarnya secara keseluruhan untuk menentukan habitus dan habitatnya. Diambil pula morfologinya seperti daun, bunga, buah, dan batang. Diberi alkohol sebagai zat pengawet, dimasukan dalam plastik dan diberi etiket gantung setiap spesies yang ditemukan. Contoh etiket gantung pada gambar

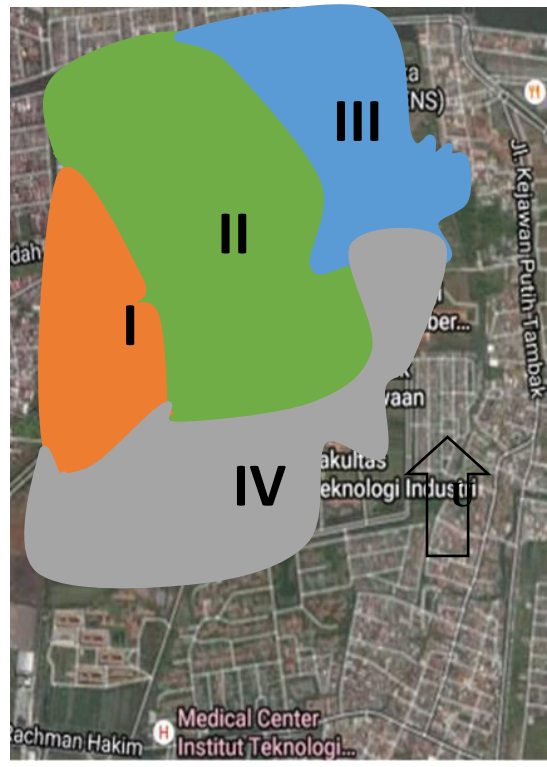

Keterangan :

I : : Area hutan kampus

II : Area gedung kampus

III : Area gedung Nasdec,

Robotika, dan Hidrodinamika

IV : Area perumahan dosen dan asrama mahasiswa

Gambar 1. Daerah pengambilan sampel.

\section{2) Identifikasi Sampel}

Sampel yang didapat dari kampus ITS dibawa ke labolatorium biosains dan teknologi tumbuhan jurusan Biologi Institut Teknologi Sepuluh Nopember Surabaya, untuk diamati morfologinya dan dicatat dalam tabel pengamatan, tabel 3.1. Selain diamati setiap spesies yang ditemukan dari setiap area didokumentasikan dalam bentuk foto. Pengambilan foto untuk bagian morfologi tumbuhan yang ada disandingkan dengan pembanding seperti penggaris. Hasil identifikasi akan dibandingkan dengan buku Panduan Pengenalan Mangrove Indonesia [3] dan Menjelajah Mangrove Surabaya [4].

3) Klasifikasi dan Taksonomi Sampel

Sampel yang telah diidentifikasi selanjutnya diklasifikasi dan diberi taksonominya merujuk pada buku Introductory Plant Biology [5].

\section{4) Analisis Data}

Penelitian ini menggunakan analisis data secara deskriptif kualitatif. Parameter data yang digunakan adalah hasil pengamatan sampel dan perbandingan dengan literatur.

\section{HASIL DAN DISKUSI}

\section{A. Mangrove Kampus ITS}

Setelah melakukan penelitian, ditemukan 13 jenis mangrove di kampus ITS. Dua diantaranya termasuk mangrove sejati, yaitu dari spesies Bruguiera gymnorrhiza dan Rhizophora stylosa. Sementara sisanya merupakan mangrove asosiasi, yaitu: Acrostichum aerum (Paku), Barringtonia asiatica (Keben), Calotropis gigantea (Widuri), Cerbera manghas (Bintaro), Hibiscus tiliaceus (Waru), Morinda citrifolia (Mengkudu), Pandanus tectoricus (Pandan laut), Passiflora foetida (Rombusa), Ricinus communis (Jarak), Stachytarpheta jamaicensis (Pecut kuda), dan Terminalia catappa (Ketapang).

Tabel 1.

Perbedaan Bruguiera gymnorrhiza dan Rhizophora stylosa

\begin{tabular}{|c|c|c|c|}
\hline $\begin{array}{c}\mathrm{N} \\
\mathrm{O}\end{array}$ & Morfologi & $\begin{array}{c}\text { Bruguiera } \\
\text { gymnorrhiza }\end{array}$ & Rhizophora stylosa \\
\hline 1. & Akar & & \\
\hline 2. & Batang & & \\
\hline 3. & Daun & & \\
\hline 4. & Bunga & - & \\
\hline 5. & Buah & - & \\
\hline
\end{tabular}


Bruguiera gymnorrhiza dan Rhizophora stylosa merupakan mangrove sejati. Morfologi kedua tanaman tersebut berbeda. Saat pengamatan di Area IV yang didominasi oleh Rhizophora stylosa, namun terdapat 3 tumbuhan spesies Bruguiera gymnorrhiza yang terlihat berbeda morfologinya dibandingkan tumbuhan di sekitarnya. Bruguiera gymnorrhiza memiliki akar papan dan akar napas pada umumnya, namun di ITS ini ukuran tumbuhan dan akarnya masih kecil dan kurang terlihat. Akan tetapi akar napas yang menggantung terlihat jelas saat pengamatan. Batangnya berwarna coklat, kasar, dan memiliki lentisel. Daunnya berwarna hijau pada bagian atasnya berwarna lebih gelap dari bagian bawahnya. Rhizophora stylosa memiliki akar tunjang. Batang berwarna abu - abu halus bercelah. Daun berbentuk elips melebar dengan ujung runcing, seperti tabel 1.

Pembagian 4 area jelajah berdasarkan kerapatan vegetasi menghasilkan penemuan yang beragam. Mangrove sejati Bruguiera gymnorrhiza dan Rhizophora stylosa hanya ditemukan di Area IV. Mangrove asosiasi ditemukan di setiap area, dengan jumlah spesies yang berbeda - beda sertiap area, lihat tabel 2.

Tabel 2.

Spesies yang Ditemukan Setiap Area

\begin{tabular}{|c|c|c|c|c|c|c|}
\hline No & Spesies & $\begin{array}{c}\text { Nama } \\
\text { Daerah }\end{array}$ & I & II & III & IV \\
\hline 1. & Bruguiera gymnorrhiza & Tanjang & & & & $\sqrt{ }$ \\
\hline 2. & Rhizophora stylosa & Bakau & & & & $\sqrt{ }$ \\
\hline 3. & Acrostichum aerum & Paku & & $\sqrt{ }$ & & $\sqrt{ }$ \\
\hline 4. & Barringtonia asiatica & Keben & & $\sqrt{ }$ & & \\
\hline 5. & Calotropis gigantea & Widuri & $\sqrt{ }$ & $\sqrt{ }$ & $\sqrt{ }$ & $\sqrt{ }$ \\
\hline 6. & Cerbera manghas & Bintaro & $\sqrt{ }$ & $\sqrt{ }$ & $\sqrt{ }$ & \\
\hline 7. & Hibiscus tiliaceus & Waru & & $\sqrt{ }$ & $\sqrt{ }$ & $\sqrt{ }$ \\
\hline 8. & Morinda citrifolia & Mengkudu & & & & $\sqrt{ }$ \\
\hline 9. & Pandanus tectoricus & Pandan laut & & $\sqrt{ }$ & $\sqrt{ }$ & \\
\hline 10. & Passiflora foetida & Rombusa & $\sqrt{ }$ & & $\sqrt{ }$ & $\sqrt{ }$ \\
\hline 11. & Ricinus communis & Jarak & & $\sqrt{ }$ & & $\sqrt{ }$ \\
\hline 12. & $\begin{array}{l}\text { Stachytarpheta } \\
\text { jamaicensis }\end{array}$ & Pecut kuda & $\sqrt{ }$ & & $\sqrt{ }$ & $\sqrt{ }$ \\
\hline 13. & Terminalia catappa & Ketapang & $\sqrt{ }$ & $\sqrt{ }$ & $\sqrt{ }$ & $\sqrt{ }$ \\
\hline
\end{tabular}

B. Deskripsi dan Morfologi Mangrove Kampus ITS

Morfologi dan foto mangrove yang diambil dari 4 area diamati setiap bagiannya. Hasil pengamatan ditulis secara deskriptif. Setelah diidentifikasi ditemukan 12 familia dari 13 spesies mangrove di Kampus ITS.

\section{1) Bruguiera gymnorrhiza (Tanjang)}

Bruguiera gymnorrhiza ditemukan di asrama mahasiswa Kelompok tumbuhan Pohon, di kampus ITS ditemukan dengan ketinggian $75 \mathrm{~cm}-1 \mathrm{~m} /$ Kulit Kayu memiliki lentisel dan permukaan kasar, berwarna abu - abu. Akar papan dan memiliki akar napas yang menggantung. Daun berkulit dengan warna hijau muda hingga hijau tua. Letak daun sederhana dan berlawanan. Bentuknya elips hingga elips-lanset. Ujungnya runcing. Ukuran terkecil $3 \times 7 \mathrm{~cm}$ dan terbesar $6 \times 13 \mathrm{~cm}$. Spesies yang ditemukan tidak memiliki buah dan bunga. Namun menurut Rusila [3], bunga bergelantungan dengan panjang tangkai bunga antara 9-25 mm. Letak: di ketiak daun, menggantung. Formasi: soliter. Mahkota 10-14, putih dan coklat jika tua, panjang 13-16 mm. Kelopak 10-14, warna merah muda hingga merah, panjang 30-50. Buah melingkar spiral, bundar melintang, panjang 2-2,5 cm. Hipokotil lurus, tumpul dan berwarna hijau tua keunguan. Ukuran: Hipokotil: panjang 12-30 cm dan diameter 1,5-2 cm.

\section{2) Rhizophora stylosa (Bakau)}

Rhizophora stylosa ditemukan di Asrama Mahasiswa ITS dan Perumahan Dosen. Ada perbedaan dari Rhizophora stylosa yang ditemukan di Perumahan Dosen dan Asrama Mahasiswa ITS, Rhizophora stylosa yang ditemukan di Asrama Mahasiswa ITS hidup di lingkungan yang tergenang air, sedangkan di Perumahan dosen hidup tanpa tergenang air. Meskipun Rhizophora stylosa di perumahan dosen lebih tinggi dan berbuah namun akar tunjangnya kurang berfungsi sebagai penegak pohon, Karena posisi beberapa pohon miring dan terlihat akar tunjang yang tidak masuk ke tanah. Rhizophora stylosa yang berada di Asrama Mahasiswa ITS memiliki pohon yang lebih tegak, namun belum berbuah dan ukuran lebih kecil. Kelompok tumbuhan pohon, di kampus ITS ditemukan dengan ketinggian $75 \mathrm{~cm}-3 \mathrm{~m}$. Kulit kayu halus, bercelah, berwarna abu - abu. Akar memiliki akar tunjang dengan panjang $30 \mathrm{~cm}-75 \mathrm{~cm}$. Daun berbentuk elips melebar, letak daun sederhana dan berlawanan. Ujung daun meruncing. Ukuran $5 \mathrm{~cm}-10 \mathrm{~cm}$ Bunga terletak di ketiak daun, memiliki 4 kelopak berwarna kuning kehijauan dan 4 mahkota berwarna putih. Buah ditemukan ketika penjelajahan namun tidak bisa diambil dan diamati, karena letak buah yang berada terlatu tinggi untuk diambil. Sehingga pengamatan hanya berdasarkan foto dan ukuran mengacu pada Rusila [3] panjangnya 2,5-4 cm, berbentuk buah pir kecil, berwarna coklat, berisi 1 biji fertil. Hipokotil silindris, berbintil agak halus. Leher kotilodon kuning kehijauan ketika matang. Ukuran: Hipokotil: panjang 20-35 cm (kadang sampai $50 \mathrm{~cm}$ ) dan diameter 1,5-2,0 cm.

3) Acrostichum aerum (Paku)

Acrostichum aerum (paku) Ditemukan di Area II dan Area IV. Kelompok tumbuhan terna berbentuk tandan di tanah. Di kampus ITS ditemukan dengan besar dan tinggi $40 \mathrm{~cm}-90$ $\mathrm{cm}$ Panjang daun $15-30 \mathrm{~cm}$. Memiliki banyak anak daun antara 10 - 22. Ujung anak daun membulat atau tumpul. Pada saat pengamatan spora tidak terlihat namun menurut Rusila [3] spora berbentuk tetrahedral.

\section{4) Barringtonia asiatica (Keben)}

Barringtonia asiatica (keben) kelompok tumbuhan Pohon. Di ITS ditemukan dengan tinggi $1-20 \mathrm{~m}$. Kulit kayu: berwarna cokelat abu-abu, ranting tebal. Daun berwarna hijau tua, agak tebal, dan urat daun tampak jelas. Unit dan letak: sederhana dan bersilangan. Bentuk: bulat telur terbalik. Ujung daun agak membundar, tumpul. Ukuran: $8-40$ x $5-15 \mathrm{~cm}$.

Bunga menggantung, menggerombol. Memiliki daun mahkota 4 berwarna putih hingga kuning. Kelopak bunga berwarna putih hingga kehijauan. Benang sari banyak. Buah berukuran besar, permukaan halus dan berbentuk tetrahedral atau piramid. Berwarna hijau, dan bisa berubah menjadi cokelat. Terdapat satu biji berukuran besar di dalamnya.

\section{5) Calotropis gigantea (Widuri)}

Calotropis gigantea (widuri) ditemukan di seluruh area pengamatan. Termasuk kelompok tumbuhan herba atau semak. Di ITS di temukan dengan ketinggian $30-80 \mathrm{~cm}$. Posisi daun horizontal, permukaan daun (atas maupun bawah) 
dilapisi oleh rambut - rambut halus yang berwarna agak putih seperti tepung. Unit dan letak: sederhana dan berlawanan. Bentuk: bulat telur melebar. Ujung: membundar. Ukuran: 10$20 \times 3-5 \mathrm{~cm}$.

Bunga memiliki tandan dan tangkai yang panjang. Letaknya pada ketiak daun. Formasinya seperti payung yang sedang dibuka. Daun mahkota berwarna putih agak ungu, ukuran diameter 6-10 mm. Kelopak bunga: 5, seperti piramid dan kaku, berwarna ungu agak putih, diameter 3-4 cm. Buah berbentuk bulat seperti kapsul dan di dalamnya terdapat banyak biji-biji yang permukaannya berambut halus. Ukuran diameternya buah 10-15 mm.

\section{6) Cerbera manghas (Bintaro)}

Cerbera manghas (bintoro) Termasuk kelompok tumbuhan pohon. Ketinggian yang ditemukan di kampus ITS antara 3 8 meter. Kulit batang bercelah dengan warna coklat. Memiliki lentisel dan getah. Akar menjalar. Memiliki bentuk daun lanset. Ujung daun meruncing. Unit dan letak sederhana dan bersilangan. Ukuran 8-20 x 2-6 cm.

Bunga terletak di ujung cabang. Formasinya berkelompok secara tidak beraturan. Memiliki 5 daun mahkota yang putih bersih dengan bagian pusat berwarna jingga hingga merah muda-merah. Kelopak bunga: 5, putih kehijauan. Buah berwarna hijau ketika muda, kemudian berubah menjadi merah da menggelap saat tua.

\section{7) Hibiscus tiliaceus (Waru)}

Hibiscus tiliaceus (waru) termasuk tumbuhan pohon yang tumbuh tersebar dengan ketinggian hingga mencapai $15 \mathrm{~m}$. Kulit kayu halus, burik-burik, berwarna cokelat keabu-abuan. Daun agak tebal, berkulit dan permukaan bawah berambut halus dan berwarna agak putih. Unit dan letak daun sederhana dan bersilangan. Bentuk daun seperti hati. Ujung daun meruncing. Ukuran 7,5-15 x 7,5-14,5 cm.

Bunga tidak ditemukan saat pengamatan, namun menurut Rusila [3] bunga berbentuk lonceng. Saat mekar berwarna kuning muda dengan warna jingga/gelap di bagian tengah dasar. Dasar dari gagang tandan bunga yang memanjang ditutupi oleh pinak daun yang kemudian akan jatuh dan menyisakan tonjolan berbentung cincin. Letak bunga di ketiak daun. Formasi bunga soliter atau berkelompok (2-5). Daun mahkota berwarna kuning, diameter 5-7 cm. Kelopak bungaberjumlah 5, bergerigi. Tangkai putik berjumlah bunga 5 (tidak menyatu), dengan kepala putik berwarna ungu kecoklatan Buah membuka menjadi 5 bagian, dan memiliki biji khas yang berambut. Ukuran buah diameter buah sekitar 2 $\mathrm{cm}$.

\section{8) Morinda citrifolia (Mengkudu)}

Morinda citrifolia termasuk tumbuhan perdu hingga pohon kecil. Tinggi yang ditemukan di ITS berkisa antara $1-5$ meter. Daun tebal, bertangkai pendek, warnyanya hijau tua mengkilap, tepi daun rata. Tulang daun menyirip kearah pinggiran daun dan tampak sangat jelas. Unit dan Letak daun sederhana dan berlawanan. Bentuk: bulat telur hingga elips. Ujung: meruncing. Ukuran:5 x $10 \mathrm{~cm}$ sampai 10 x $18 \mathrm{~cm}$.

Bunga berwarna putih, harum dan mudah rontok. Letak: di ketiak daun. Formasi: payung dengan 5-8 bunga. Mahkota berjumlahnya 5, warna putih.

Buah Lonjong bulat telur seperti kapsul dan penuh dengan benjolan. Ketika masih mentah berwarna hijau muda, ketika matang agak kekuningan, lembek dan berair. Biji kecil-kecil, coklat kehitaman dan banyak. Ukuran: panjang 5-10 cm.

9) Pandanus tectoricus (Pandan laut)

Pandanus tectoricus (pandan laut). Termasuk jenis tumbuhan pohon dapat mencapai ketinggian hingga $6 \mathrm{~m}$. Daun berduri pada sisi daun dan ujungnya tajam. Panjang antara 0,5-2 meter. Bunga tidak ditemukan saat pengamatan, namun menurut Rusila [3] letak bunga di ujung. Benang sari banyak. Formasi bunga seperti payung. Buah seperti buah nanas dan ketika matang warnanya merah.

\section{0) Passiflora foetida (Rombusa)}

Passiflora foetida (rombusa) terdapat di bagian dalam hutan kampus ITS. Termasuk tumbuhan Terna merambat, panjang 1,5-5 m. Memiliki alat pembelit yang beruntaian seperti spiral. Daun berwarna hijau kekuningan hingga hijau muda mengkilat seperti ada lapisan lilin, berambut halus, bertangkai 2-10 cm. Unit dan letak sederhana dan bersilangan. Bentuknya seperti jantung, lebar menjari dengan tiga lekukan. Ujungnya meruncing. Ukuran: 5 x $4 \mathrm{~cm}$ sampai 13 x $12 \mathrm{~cm}$.

Bunga tidak ditemukan saat pengamatan namun menurut Rusila [3] warnanya agak putih hingga ungu muda/pucat, pada bagian tengahnya jauh lebih ungu. Letak: di ketiak tangkai daun. Formasinya soliter. Daun mahkotanya berbentuk bulat telur terbalik, diameter hingga $5 \mathrm{~cm}$. Benang sarinya banyak, putih dan panjangnya dapat melampaui ukuran panjang mahkota bunga.

Buahnya berbentuk bulat seperti kelereng, kadang agak lonjong. Kulit buah hijau jika mentah dan menjadi getas dan kuning ketika matang. Buah dibungkus oleh serabut yang berambut banyak. Di dalam buah banyak dijumpai biji. Ukurannya diameter buah 1,5-3,0 cm.

\section{1) Ricinus communis (Jarak)}

Richinus communis (jarak) tumbuhan berbentuk perdu tegak dapat mencapai ketinggian hingga $3 \mathrm{~m}$. Daun seperti daun singkong, tapi tepinya bergerigi, urat daunnya rapat dan jelas. Warna daun hijau tua di permukaan atas dan hijau muda di permukaan bawah. Tangkai daun panjang berwarna hijau hingga merah bata. Unit \& Letak: sederhana tunggal dan bersilangan. Bentuk daun menjari dengan jumlah jari $7-9$. Ujung daun meruncing. Ukuran diameter 10-40 cm. Bunga majemuk, berwarna kuning oranye dan berkelamin satu. Buah berbentuk bulat bersegmen (ada 3 segmen) dan berambut (seperti buah rambutan). Warna buah hijau dan bergerombol pada tandan yang panjang. Satu tandan dapat berisikan sekitar $30-40$ buah.

\section{2) Stachytarpheta jamaicensis (Pecut kuda)}

Stachytarpheta jamaicensis (pecut kuda) ditemukan di Area I, II, dan IV. Bentuk tumbuhan terna, tumbuh tegak terburai ke samping membentuk semak, tinggi mencapai 1 meter.

Daunnya memuliki permukaan daun kasar dan guratan guratan / lekukan di permukaannya tampak jelas. Unit dan letak: sederhana dan berlawanan. Bentuknya bulat telur, tepi bergerigi, tidak berambut. Ujungnya meruncing. Ukuran: $1 \mathrm{x}$ 2,5 cm sampai $3,5 \times 6 \mathrm{~cm}$.

Bunga tidak ditemukan saat pengamatan namun menurut Rusila [3] bunganya terdapat pada tandan yang panjangnya mencapai 4-20 cm seperti pecut, bunga duduk tanpa tangkai. Bunga mekar tidak serentak, ukurannya kecil berwarna ungu kebiruan dan putih. Letak: di ketiak daun. Formasi: bulir pada tandan yang panjang. 


\section{3) Terminalia catappa (ketapang)}

Terminalia catappa (ketapang) ditemukan di seluruh area pengamatan. Termasuk kelompok tumbuhan pohon. Ketinggian yang ditemukan di ITS 7-15 m. Ukuran Daun Sangat lebar, umumnya memiliki 6-9 pasang urat. Unit dan Letak: sederhana dan bersilangan. Berbentuk bulat telur terbalik. Ujung: membundar. Ukuran: 8-25 x 5-14 cm.

Tandan bunga panjangnya $8-16 \mathrm{~cm}$. Bunga berwarna putih atau hijau pucat dan tidak bergagang. Sebagian besar dari bunga merupakan bunga jantan, dengan atau tanpa tangkai putik yang pendek. Terletak di ketiak daun. Formasi berbulir. Kelopak bunga halus di bagian dalam [3]. Buah menyerupai almond. Bersabut dan cangkangnya sangat keras. Ukuran 5-7 $\mathrm{cm} \times 4 \times 5,5 \mathrm{~cm}$. Kulit buah berwarna hijau hingga hijau kekuningan.

\section{KESIMPULAN}

Berdasarkan hasil penelitian yang telah dilakukan dapat disimpulkan bahwa terdapat 13 spesies mangrove di kampus ITS. Terdiri atas: Bruguiera gymnorrhiza, Rhizophora stylosa, Acrostichum aerum, Barringtonia asiatica, Calotropis gigantean, Cerbera manghas, Hibiscus tiliaceus, Morinda citrifolia, Pandanus tectoricus, Passiflora foetida, Richinus communis, Stachytarpheta jamaicensis, dan Terminalia catappa. Ketiga belas spesies tersebut berasal dari 12 familia, yaitu: Rhizophoraceae, Pteridaceae, Lecythidaceae, Asclepiadaceae, Apocynaceae, Malvaceae, Rubiaceae, Pandanaceae, Passifloraceae, Euphorbiaceae, Verbenaceae, dan Combretaceae. Manfaat dari mangrove di kawasan kampus ITS sebagian besar sebagai tanaman obat, pangan, dan bahan bangunan. Meskipun begitu ada beberapa jenis mangrove yang bermanfaat dibidang pertanian.

\section{DAFTAR PUSTAKA}

[1] Gunarto, "Konservasi mangrove sebagai pendukung sumber hayati perikanan pantai," J. Litbang Pertan., vol. 23, no. 1, pp. 15-21, 2004.

[2] D. Z. Irwan, "Peranan bentuk dan Struktur hutan kota terhadap kualitas lingkungan kota," Institut Pertanian Bogor, 1994.

[3] Y. Rusila Noor, M. Khazali, and I. N. N. Suryadiputra., "Panduan Pengenalan Mangrove di Indonesia," Bogor, 2012.

[4] D. Saptarini, F. M. Kamal, N. D. Kuswytasari, and A. Sulisetyono, "Menjelajah Mangrove Surabaya," Surabaya, 2012.

[5] K. Stern, Introductory Plant Biology, 8th ed. California: Mc Graw Hill, 2000. 